\title{
The Way of Reducing Current Values in Optical Ground Wires at Asymmetrical Faults on Overhead Transmission Lines
}

\author{
Georgiy Egamnazarov (Senior Researcher, Electrical Power Stations Networks and Systems Department of \\ Tashkent State Technical University)
}

\begin{abstract}
Given the fact that the installing costs of an optical ground wire on overhead lines directly depend on its crosssection, which in turn depends on the level of fault current it should withstand, in order to reduce these current values in the optical ground wire, I suggested performing its isolated descents from the end towers of the line with its transition to an optical cable. The research was carried out on the example of a $500 \mathrm{kV}$ overhead line in the National Electric Power Grid. The Method of Symmetrical Components for calculating asymmetrical fault currents was not used; therefore, calculations were carried out on the base of presenting the line as a multi-wire system for the considered case as a five-wire system (optical ground wire, steel ground wire, and three phase wires). Such approach allows taking into account the initial asymmetry of the line parameters and modeling any kind of asymmetrical faults. The analyses of calculated results were performed. The conclusive evidence that the optical ground wire isolated descents from the end towers of the line give the possibility of reducing the level of maximal fault current distribution values in it and therefore its cross section, is presented.
\end{abstract}

Keywords - Fault currents; Grounding; Transmission lines.

\section{INTRODUCTION}

In recent years, the suspension of optical fiber composite ground wires (the IEEE standard) on overhead power transmission lines (PTL), known as optical ground wires $(\mathrm{OPGW})$, is becoming increasingly popular.

OPGW serves two purposes [1]:

1) to replace a conventional ground wire $(\mathrm{GW})$, to protect the transmission system from lightning, and to serve as a conductive medium for carrying fault currents to ground;

2) to provide telecommunications capacity utilizing optical fibers.

As such, an OPGW cable is required to withstand the effects from installation and long-term in-service exposure to mechanical, electrical, and environmental loads without significant degradation in performance.

In order to withstand the effect of electrical exposure on OPGW, i.e., the thermal effect of currents at asymmetrical faults, it is necessary to test and choose OPGW with proper features on a project stage. The loss of thermal stability of OPGW leads to the damage cause of connection loss. At the same time, the use of OPGW with a large cross section that has high thermal stability all over the length on overhead PTL can lead to unnecessarily increase in the costs of the project, because of the significant dependence of the price of OPGW on its cross section. Also, it can lead to the increase in mechanical loads on the towers, which will require additional costs to strengthen them for the reason of proportional dependence of OPGW mass on its cross section [2]-[4].

Given the fact that the project costs on installing OPGW directly depend on the OPGW cross-section, which in turn depends on the level of fault current it should withstand, the solution for reducing these current values by performing its isolated descents with its transition to an optical cable from the end towers of the line was studied. It was proved that this solution gives the possibility of reducing the level of fault current distribution values in OPGW and, therefore, also of decreasing its cross section, thus allowing to save the total costs of the project. This approach on the example of the $500 \mathrm{kV}$ PTL Sirdarya-Novoangren in the National Electric Power Grid was implemented and analyzed.

The method of symmetrical components (MSC) for calculating asymmetrical fault currents [5] was not used. The implementation of the MSC requires a strong symmetry of the three-phase system of wires; at the same time, the influence of the factors that violate the initial symmetry of the system by itself requires estimation for using the MSC. These factors are:

- the suspension of different phase wires on towers;

- the suspension of GW;

- phase wires and GW geometric positions on towers;

- the presence of OPGW that has high conductivity.

Therefore, fault current calculations were carried out on the base of presenting the overhead PTL as a multi wire system [6], [7], where the number of wires in the system is defined by the sum of suspended conductors (wires) that have electromagnetic connection between each other. So, for double-circuit overhead PTL on common towers and with the suspension of one GW, the total number of wires is determined as seven (a seven-wire system). For double-circuit PTL on different towers with the suspension of two GW on each circuit, the line is presented as a ten-wire system. Accordingly, for one circuit PTL without GW, the line is presented as a three-wire system; with one GW - as a fourwire system; and with two GW - as a five-wire system. At the same time, the system characteristics are determined not only by the parameters of wires but also by the geometry of their mutual positions on towers, the ground resistances, and the modes of GW groundings on the different sections of PTL.

The presentation of an overhead PTL as a multi-wire system allows: 
- taking into account the asymmetry of overhead PTL line parameters;

- modeling any kind of asymmetrical faults;

- modeling the modes of GW groundings on the towers and in the loops of substation groundings;

- modeling different types of GW descents from the end towers of an overhead PTL.

\section{The PRINCIPLE OF FAUlt CURRENT CALCUlATIONS}

The model of an electrical power network for performing the calculations where an overhead PTL is presented as a fivewire system is shown in Fig. 1.

The overhead PTL was divided into three sections according to the ground characteristics and the types of suspended phase wires on the towers along the whole length of the line (Table I). GW and phase wire parameters are presented in Table II. The tower type was given also along the whole length of the line; its geometrical dimensions are presented in Fig. 2.

TABLE I

OVERHEAD PTL SECTIONS

\begin{tabular}{|c|c|c|c|c|}
\hline \multirow{2}{*}{$\begin{array}{c}\text { Section No. } \\
\text { from the side } \\
\text { of Sirdarya }\end{array}$} & \multirow{2}{*}{$\begin{array}{c}\text { Section lengths } \\
(\mathrm{km})\end{array}$} & $\begin{array}{c}\text { Soil } \\
\text { resistivity } \\
\rho(\Omega \mathrm{m})\end{array}$ & \multicolumn{2}{|c|}{ The types of phase wires } \\
\hline \multirow{2}{*}{1} & 38 & \multirow{2}{*}{$500-700$} & Phase A & $3 \times$ ACSR 300/66 \\
\cline { 4 - 5 } & \multirow{2}{*}{2} & \multirow{2}{*}{$50-150$} & Phase B & $3 \times$ ACSR 300/66 \\
\cline { 4 - 5 } & \multirow{2}{*}{3} & & Phase C & $3 \times$ ACSR 300/66 \\
\cline { 4 - 5 } & \multirow{2}{*}{31.7} & \multirow{2}{*}{1000} & Phase A & $3 \times$ ACSR 300/66 \\
\cline { 4 - 5 } & & & Phase C & $3 \times$ ACSR 300/66 \\
\cline { 4 - 5 } & & & Phase A & 3 ACSR 300/66 \\
\cline { 4 - 5 } & & & Phase C & 3 ACSR 300/66 \\
\hline
\end{tabular}

The type of OPGW was given as DABB 12E9/125 AA/ACS 092/44, for steel GW - as PT-70 (PT stands for the type of contact between the layers of wire - Point Touch).

For each of the sections of the overhead PTL, with the help of John R. Carson's equations and their modifications [8], [9], the matrices of self and mutual series specific resistances and inductances and self and mutual specific shunt capacitive susceptances, each with the size of $5 \times 5$, were calculated. These matrices for the first section of the overhead PTL are presented in Table III. The matrices for the second and the third section of the line are not presented as they are too space consuming.

TABLE II

WIRE PARAMETERS

\begin{tabular}{|c|c|c|c|}
\hline The type of wire & $\begin{array}{c}\text { Conductor } \\
\text { diameter } \\
D(\mathrm{~mm})\end{array}$ & $\begin{array}{c}T / D \\
\text { ratio }\end{array}$ & $\begin{array}{c}\text { Resistivity } \\
\rho(\Omega / \mathrm{km})\end{array}$ \\
\hline PT-70 & 11 & 0.5 & 2.33 \\
\hline DABB 12E9/125AA/ACS 092/44 & 16.0 & 0.384 & 0.28 \\
\hline $3 \times$ ACSR-300/66 & 24.5 & 0.285 & 0.102 \\
\hline $3 \times$ ACSR-400/51 & 27.5 & 0.332 & 0.075 \\
\hline
\end{tabular}

The $T / D$ value equal to 0.5 in Table II indicates a solid conductor.

Block matrices of self and mutual series and shunt capacitive admittances for each of spans are calculated according to (1) and (2):

$$
\begin{gathered}
Y_{i j}=\left(L_{\mathrm{span}} Z_{0 \mathrm{sec}}\right)^{-1}, \\
B_{C i i}=L_{\mathrm{span}} B_{C 0 \mathrm{sec}},
\end{gathered}
$$

where

$L_{\text {span }}$ - the length of the span between two neighboring towers;

$Z_{0 \text { sec }}$ - the matrices of specific self and mutual series impedances;

$B_{C 0 \text { sec }}$ - the matrices of specific self and mutual shunt capacitive susceptances.

For the considered case, mean span lengths were given (Table IV).

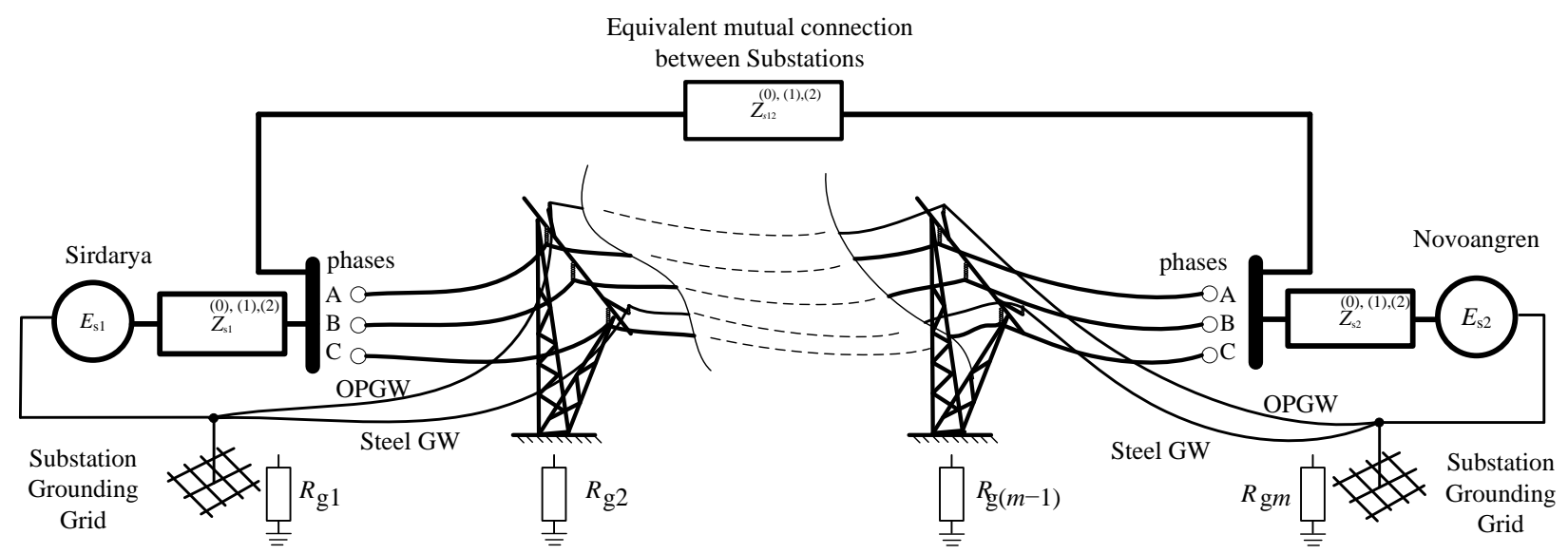

Fig. 1. The model of PTL presented as a five-wire system $\left(Z_{\mathrm{s} 1}^{(0),(1),(2)}\right.$ and $Z_{\mathrm{s} 2}^{(0),(1),(2)}$ - system equivalent impedances of zero, positive, and negative components correspondingly for each substation; $Z_{\mathrm{s} 12}^{(0),(1),(2)}$ - system equivalent mutual impedances of zero, positive, and negative components between substations correspondingly; $E_{\mathrm{S} 1}$ and $E_{\mathrm{S} 2}$-system equivalent EMF for each substation; $R_{\mathrm{g}}$-tower and substation grounding grid resistances). 
The complete cycle of transposition on the overhead PTL was modeled according to [9]. The total number of towers on PTL was given as 346 (not counting substation buses) with the transposition towers Nos 130 and 243, correspondingly.

The values of tower groundings were taken the maximally acceptable in accordance with the soil resistivity of the sections of the line [10]. The reason for taking the maximally acceptable tower groundings was that it allows determining the maximally possible flowing currents in GW.

Therefore, for sections with soil resistivity: $100<\rho<500 \Omega \mathrm{km}, \quad R_{\mathrm{g}}=15 \Omega ; \quad 500<\rho<1000 \Omega \mathrm{km}$, $R_{\mathrm{g}}=20 \Omega ; 1000<\rho<5000 \Omega \mathrm{km}, R_{\mathrm{g}}=30 \Omega$.

On the bus bars for each of the stations, grounding resistances were given as $R_{\mathrm{g}}=0.5 \Omega$, and the span length from the end towers to the bus bars was given as $L=50 \mathrm{~m}$.

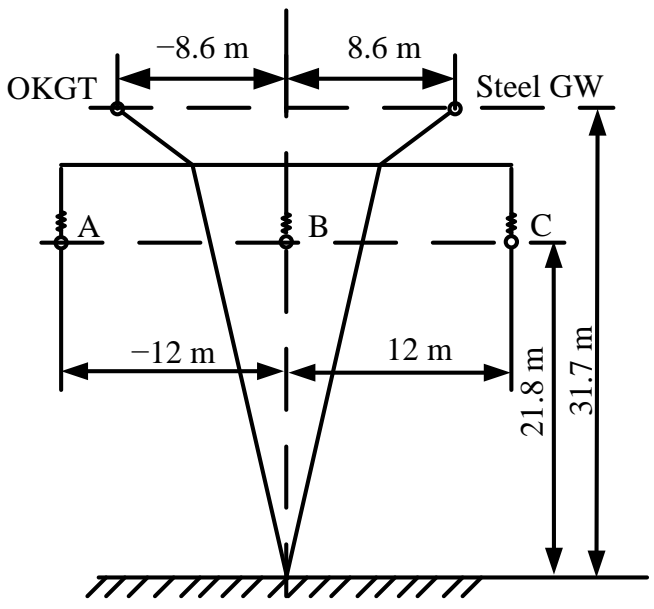

Fig. 2. The geometrical dimensions of the tower.

TABLE III

Calculated Parameters For the First SECTION

\begin{tabular}{|c|r|r|r|r|r|}
\hline \multicolumn{7}{|c|}{ The matrix of resistances $R(\Omega / \mathrm{km})$} \\
\hline & Phase A & \multicolumn{1}{c|}{ Phase B } & \multicolumn{1}{c|}{ Phase C } & \multicolumn{1}{c|}{ PT } & OPGW \\
\hline Phase A & 0.0831 & 0.0488 & 0.0488 & 0.0486 & 0.0486 \\
\hline Phase B & 0.0488 & 0.0831 & 0.0488 & 0.0486 & 0.0486 \\
\hline Phase C & 0.0488 & 0.0488 & 0.0831 & 0.0486 & 0.0486 \\
\hline PT & 0.0486 & 0.0486 & 0.0486 & 2.3784 & 0.0484 \\
\hline OPGW & 0.0486 & 0.0486 & 0.0486 & 0.0484 & 0.3286 \\
\hline \multicolumn{7}{|c|}{ The matrix of inductances $L(\mathrm{H} / \mathrm{km})$} \\
\hline Phase A & $1.995 \times 10^{-3}$ & $1.053 \times 10^{-3}$ & $9.153 \times 10^{-4}$ & $1.089 \times 10^{-3}$ & $9.324 \times 10^{-4}$ \\
\hline Phase B & $1.053 \times 10^{-3}$ & $1.995 \times 10^{-3}$ & $1.053 \times 10^{-3}$ & $1.049 \times 10^{-3}$ & $1.049 \times 10^{-3}$ \\
\hline Phase C & $9.153 \times 10^{-4}$ & $1.053 \times 10^{-3}$ & $1.995 \times 10^{-3}$ & $9.324 \times 10^{-3}$ & $1.089 \times 10^{-3}$ \\
\hline PT & $1.089 \times 10^{-3}$ & $1.049 \times 10^{-3}$ & $9.324 \times 10^{-4}$ & $2.655 \times 10^{-3}$ & $9.962 \times 10^{-4}$ \\
\hline OPGW & $9.324 \times 10^{-4}$ & $1.049 \times 10^{-3}$ & $1.089 \times 10^{-3}$ & $9.962 \times 10^{-4}$ & $2.576 \times 10^{-3}$ \\
\hline \multicolumn{7}{|c|}{ The matrix of capacitances $C(\mathrm{~F} / \mathrm{km})$} & \\
\hline Phase A & $1.09 \times 10^{-8}$ & $-1.31 \times 10^{-9}$ & $-3.05 \times 10^{-10}$ & $-1.25 \times 10^{-9}$ & $-3.72 \times 10^{-10}$ \\
\hline Phase B & $-1.31 \times 10^{-9}$ & \multicolumn{5}{|c|}{$1.11 \times 10^{-8}$} & $-1.30 \times 10^{-9}$ & $-9.10 \times 10^{-10}$ & $-9.56 \times 10^{-10}$ \\
\hline Phase C & $-3.05 \times 10^{-10}$ & $-1.30 \times 10^{-9}$ & $1.09 \times 10^{-8}$ & $-3.51 \times 10^{-10}$ & $-1.31 \times 10^{-9}$ \\
\hline PT & $-1.25 \times 10^{-9}$ & $-9.10 \times 10^{-10}$ & $-3.51 \times 10^{-10}$ & $6.52 \times 10^{-9}$ & $-5.45 \times 10^{-10}$ \\
\hline OPGW & $-3.72 \times 10^{-10}$ & $-9.56 \times 10^{-10}$ & $-1.31 \times 10^{-9}$ & $-5.45 \times 10^{-10}$ & $6.82 \times 10^{-9}$ \\
\hline
\end{tabular}

The system equivalent parameters are presented in Table V. TABLE IV

MEAN SPAN LENGTHS ON THE OVERHEAD PTL

\begin{tabular}{|l|c|c|c|}
\hline \multicolumn{1}{|c|}{ PTL sections } & $\begin{array}{c}\text { Area } \\
\text { lengths } \\
(\mathrm{km})\end{array}$ & $\begin{array}{c}\text { Length from } \\
\text { the beginning } \\
\text { of the line }(\mathrm{km})\end{array}$ & $\begin{array}{c}\text { Mean span } \\
\text { length } \\
(\mathrm{m})\end{array}$ \\
\hline $\begin{array}{l}\text { Sirdarya - } \\
\text { Tower No. } 14\end{array}$ & 3 & 3 & 230 \\
\hline $\begin{array}{l}\text { Tower No. } 14- \\
\text { Corner Tower No. 36 }\end{array}$ & 5.5 & 8.5 & 260 \\
\hline $\begin{array}{l}\text { Corner Tower No. 36- } \\
\text { Tower No. 60 }\end{array}$ & 7.8 & 16.3 & 310 \\
\hline $\begin{array}{l}\text { Tower No. 60 - } \\
\text { Corner Tower No. } 84\end{array}$ & 7.5 & 23.8 & 325 \\
\hline $\begin{array}{l}\text { Corner Tower No. } 84- \\
\text { Corner Tower No. } 130\end{array}$ & 16.2 & 40 & 350 \\
\hline $\begin{array}{l}\text { Corner Tower No. 130- } \\
\text { Corner Tower No. } 149\end{array}$ & 6.3 & 46.3 & 335 \\
\hline $\begin{array}{l}\text { Corner Tower No. 149- } \\
\text { Corner Tower No. 218 }\end{array}$ & 24.5 & 70.8 & 350 \\
\hline $\begin{array}{l}\text { Corner Tower No. 218 - } \\
\text { Corner Tower No. 308 }\end{array}$ & 35.7 & 106.5 & 400 \\
\hline $\begin{array}{l}\text { Corner Tower No. 308- } \\
\text { Novoangren }\end{array}$ & 15 & 121.5 & 375 \\
\hline
\end{tabular}

TABLE V

SYSTEM EQUIVALENT PARAMETERS

\begin{tabular}{|c|c|c|c|}
\hline \multirow{2}{*}{ Sirdarya } & $E_{\mathrm{S} 1}(\mathrm{kV})$ & $Z_{\mathrm{s} 1}^{(1)}(\Omega)$ & $Z_{\mathrm{s} 1}^{(0)}(\Omega)$ \\
\cline { 2 - 4 } & 500 & $j 21.31$ & $j 12.58$ \\
\hline \multirow{2}{*}{ Novoangren } & $E_{\mathrm{S} 2}(\mathrm{kV})$ & $Z_{\mathrm{s} 2}^{(1)}(\Omega)$ & $Z_{\mathrm{s} 2}^{(0)}(\Omega)$ \\
\cline { 2 - 4 } & 500 & $j 18.19$ & $j 19.87$ \\
\hline $\begin{array}{c}\text { Mutual parameters } \\
\text { between substations }\end{array}$ & $\delta($ degree $)$ & $Z_{\mathrm{s} 12}^{(1)}(\Omega)$ & $Z_{\mathrm{s} 12}^{(0)}(\Omega)$ \\
\cline { 2 - 4 } & 0 & $j 280.09$ & $j 7735.5$ \\
\hline
\end{tabular}

Explanation: $\delta$ - the angle between EMF vectors of substations.

For calculating the modes, nodal equations were formed, where the state equation is written as in (3):

$$
Y U=I
$$

were

$Y$ - the nodal admittance matrix of the network, which is formed on the basis of block matrices $Y_{i j}$ and $B_{C i j}$ according to [11];

$U$ - the column vector of node voltages, where each element consists of the matrix of voltages on the wires, in the $i$-th node: $U_{i j}=\left[\dot{U}_{i 1}^{w}, \dot{U}_{i 2}^{w}, \dot{U}_{i 3}^{w}, \ldots, \dot{U}_{i(k-1)}^{w}, \dot{U}_{i k}^{w}\right]^{\mathrm{T}}$ where $\dot{U}_{i k}^{w}$ - the voltage value on the $k$-th wire in the $i$-th node $(k=1, \ldots, n, i=1, \ldots, m)$;

$I$ - the column vector of the node injected currents where each element is presented as $I_{i j}=\left[\dot{I}_{i 1}^{w}, \dot{I}_{i 2}^{w}, \dot{I}_{i 3}^{w}, \ldots, \dot{I}_{i(k-1),}^{w} \dot{I}_{i k}^{w}\right]^{\mathrm{T}}$, where $\dot{I}_{i k}^{w}$ is the value of the current in the $k$-th wire directed into the $i$-th node $(k=1, \ldots, n, i=1, \ldots, m)$; $n-$ is the number of wires in the system;

$m-$ is the number of nodes (towers) including substations.

For fault calculations, the rated type of damage was taken as a single-phase fault. The fault mode was simulated by setting in the corresponding node for the corresponding phase 
wire, a link with infinitely large transient admittance according to [12].

GW grounding simulations in the nodes on the overhead PTL were fulfilled by adding the total tower admittance, and its grounding was calculated as $Y_{\mathrm{g} i}=R_{\mathrm{Tg} i}^{-1}(i=1, \ldots, m)$, to the corresponding element of the GW's self-admittance, in the block matrices of the bus admittance matrix $Y$ in (3) as in [12].

The isolated descents of OPGW with its transition to an optical cable from the end towers of the line were simulated by setting the value of OPGW grounding admittance, from the corresponding side of a substation - equal to zero.

After forming the bus admittance matrix $Y$ with taking into account GW groundings and the type of fault in the corresponding node, by solving (3), the node voltages were defined. During solution of (3), the sparse structure of the matrix $Y$ allowed operating only with two ribbon-structure matrices (nodal-self admittances, and branch-mutual admittances), which made the algorithm even less computermemory consuming. By calculating the values of the node voltages on wires, the currents in each of the wire directed to both sides from the fault point were defined.

\section{ANALYSIS OF THE RESULTS}

On the basis of the above described algorithm for the calculation of fault currents in GW/OPGW, the program on MATLAB was written.

In Fig. 3, the voltages on the faulted wires (phase A and GW/OPGW) when moving the fault point (on towers) across the length of the line on each tower are presented. In Fig. 4, the fault currents in the phase wires flowing to the short circuit point from the left and right side of it when moving the fault point across the line on each tower are showed.

In Figs 5-8, the characteristics of current distributions in GW/OPGW when implementing different types of OPGW discents (direct and isolated) from the end towers with stepping movement of the single phase (phase A) fault point across the length of the line are presented

The diagrams in Figs 5-8 show that, after implementing the isolated descents of OPGW from the end towers of the line, the total maximal values of currents in it were decreased.

For more demonstrativeness and ease of analyses, the numerical results for different descents of OPGW are presented in Table VI. For the reason that large currents occur only on distances close to substations, the currents in OPGW only for five spans from each of substations are presented.

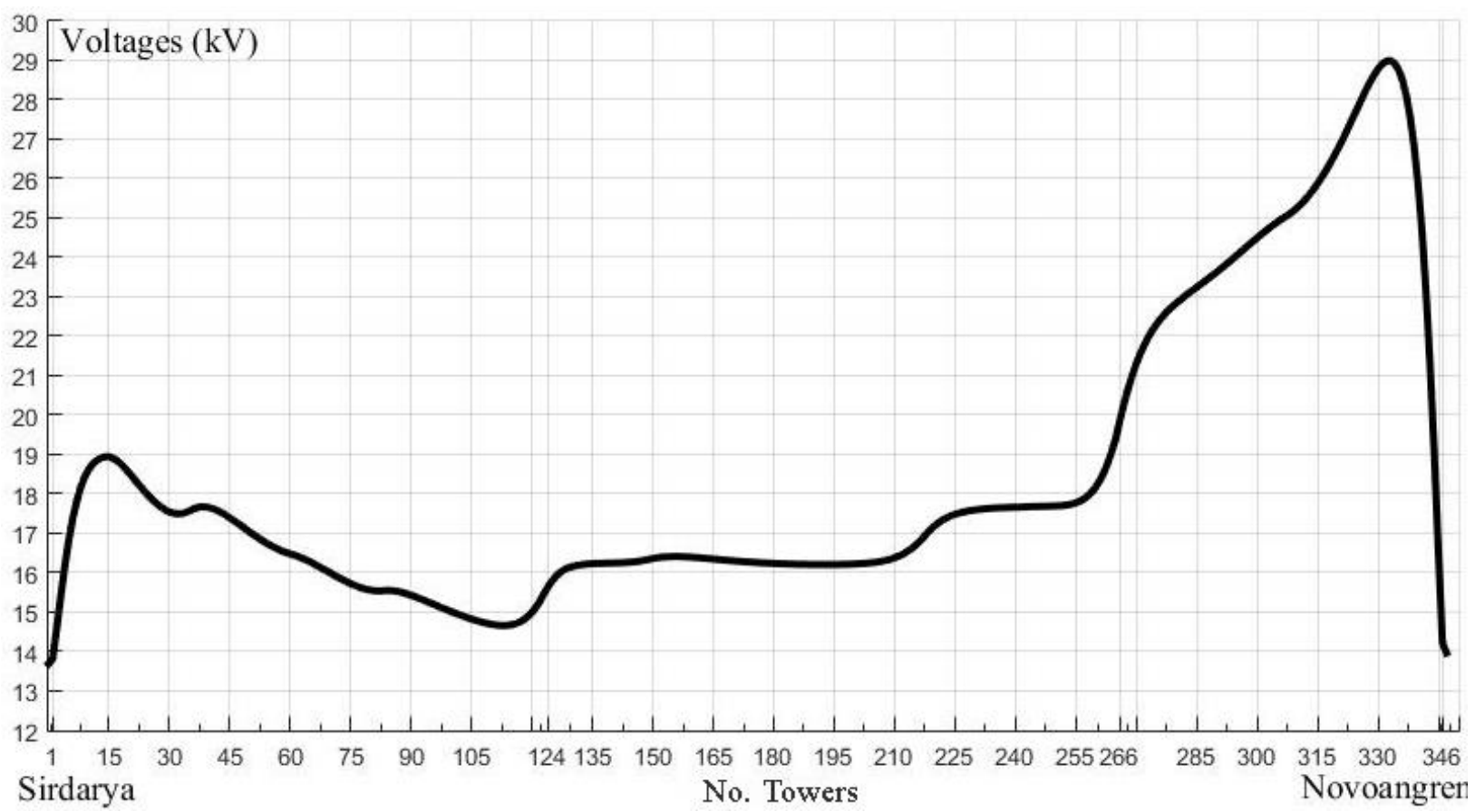

Fig. 3. Voltages on the faulted wires (phase A and GW/OPGW) when moving the fault point across the length of the line. 


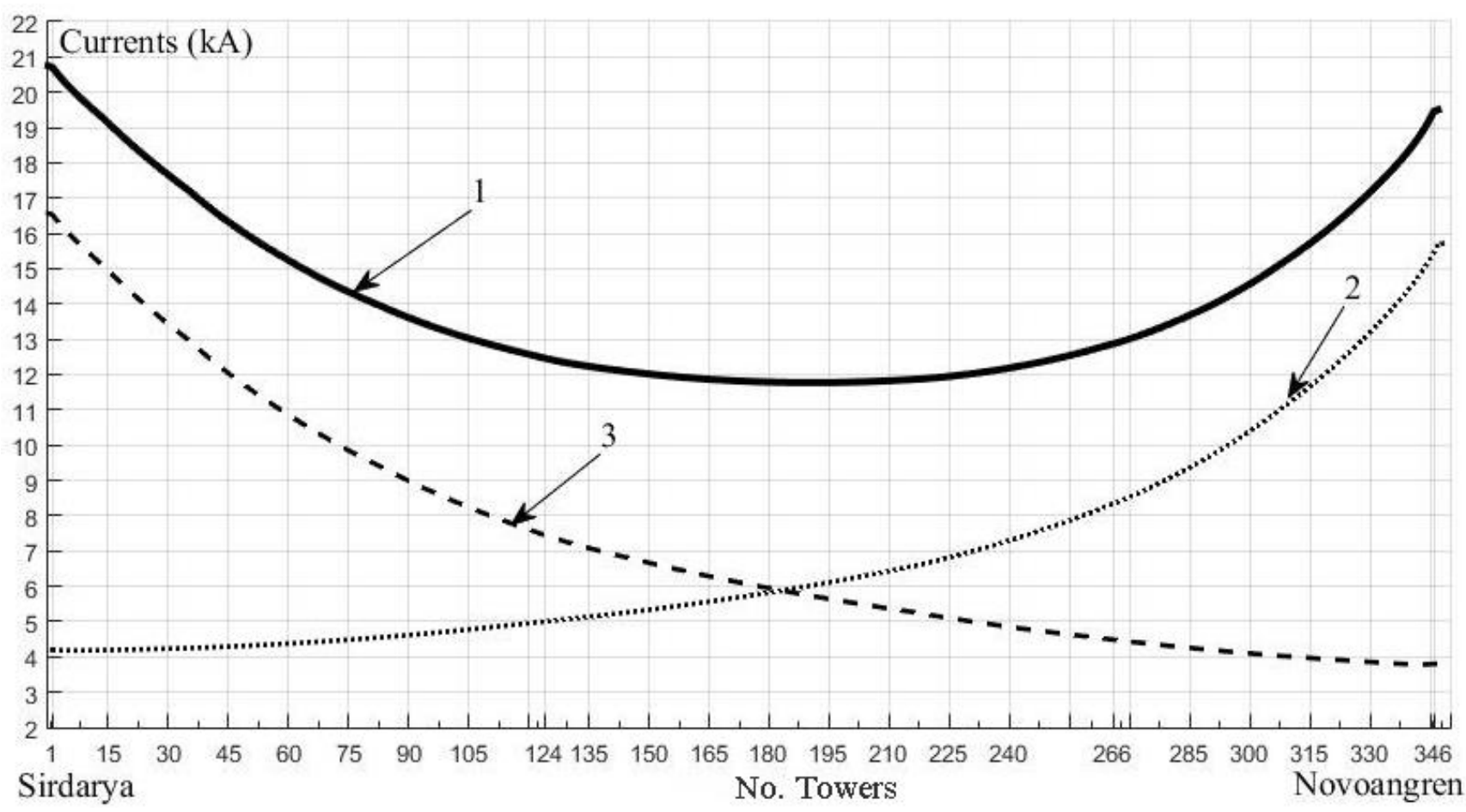

Fig. 4. Currents in phase wires with stepping movement of the fault point on the towers across the line $(1-$ the total fault current flowing to the fault point from both sides; 2 - currents in phase A directed from the side of Novoangren to the fault tower; 3 - currents in phase A directed from the side of Sirdarya to the fault tower).

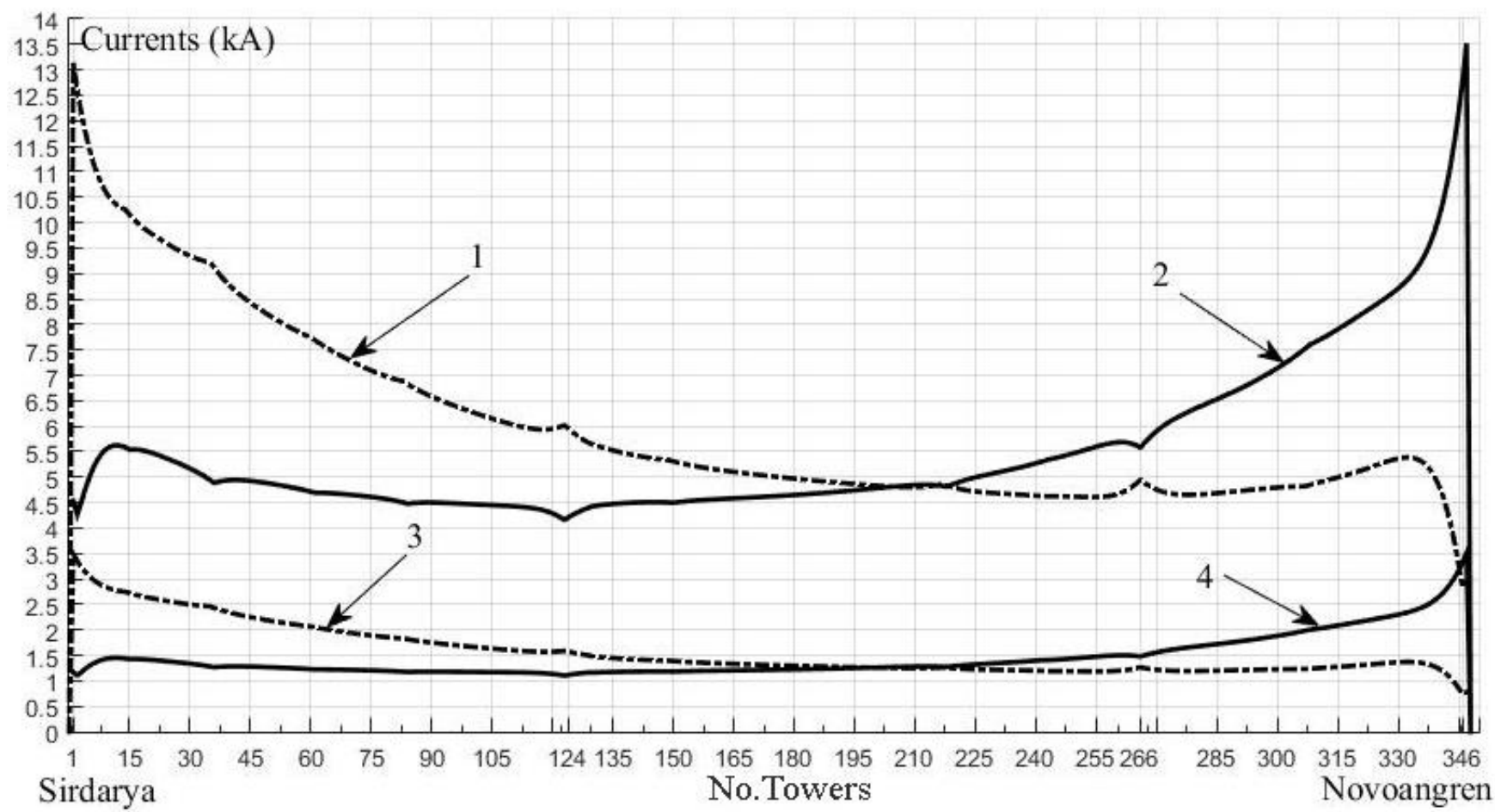

Fig. 5. The fault current distributions in GW and OPGW with stepping movement of the fault point across the line, when OPGW has direct descents from both ends of the line $(1$ - currents in OPGW directed to the side of Sirdarya from the fault tower; 2 - currents in OPGW directed to the side of Novoangren from the fault tower; 3 - currents in Steel GW directed to the side of Sirdarya from the fault tower; 4 - currents in steel GW directed to the side of Novoangren from the fault tower). 


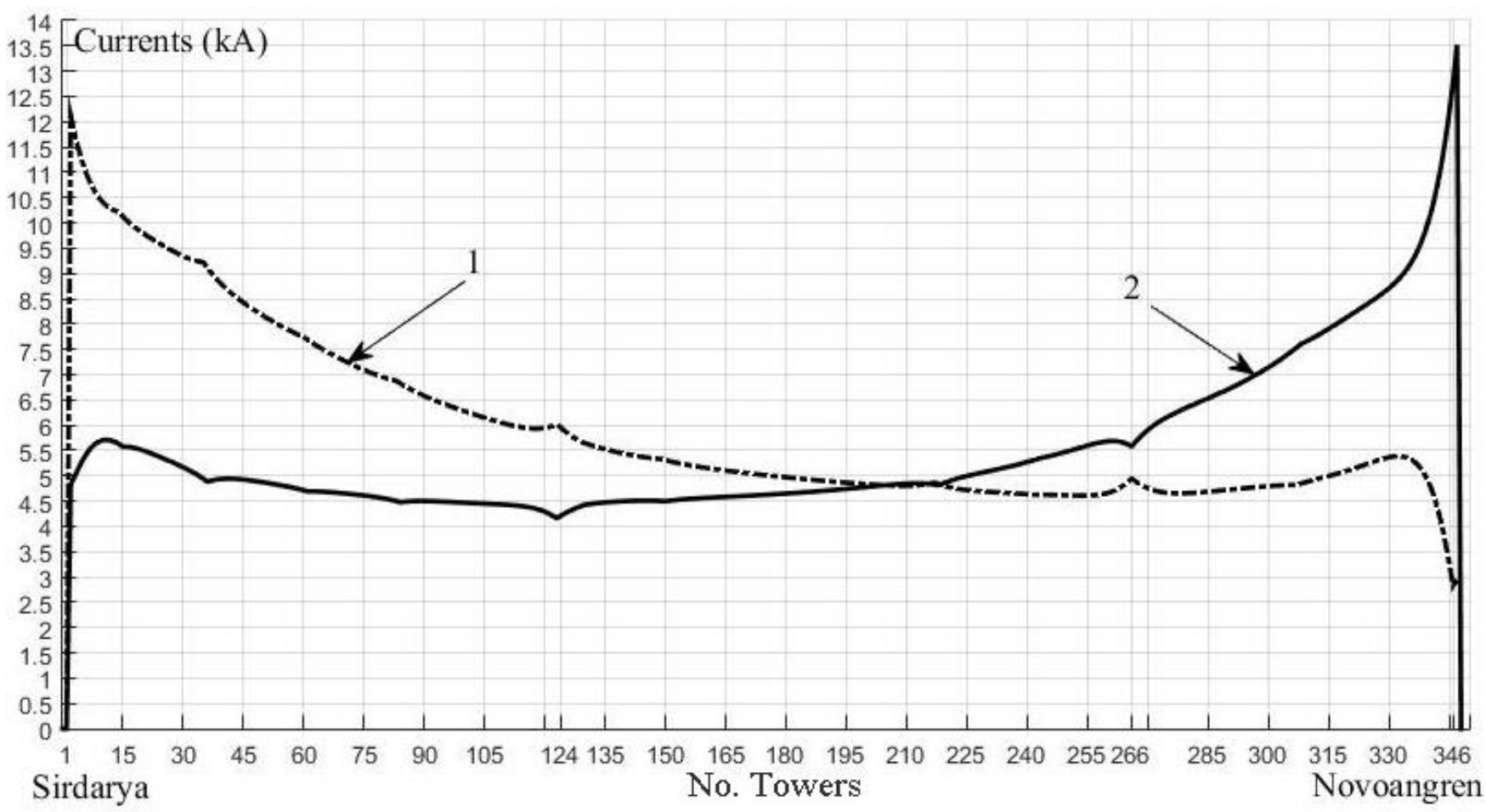

Fig. 6. The fault current distributions in OPGW with stepping movement of the fault point across the line, when OPGW has isolated descent from the side of Sirdarya and direct descent from the side of Novoangren $(1$ - currents in OPGW directed to the side of Sirdarya from the fault tower; 2 - currents in OPGW directed to the side of Novoangren from the fault tower)

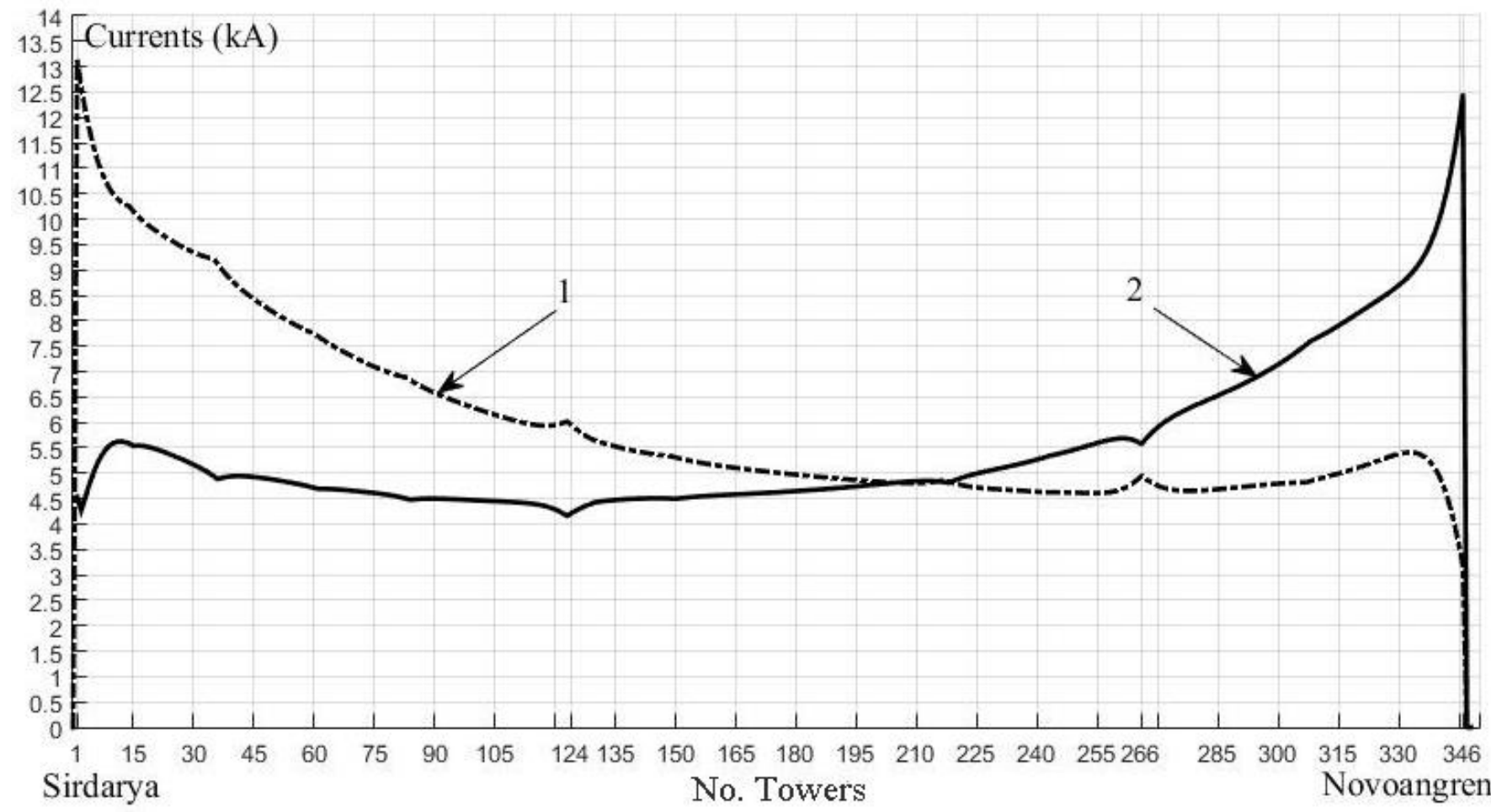

Fig. 7. The fault current distributions in OPGW with stepping movement of the fault point across the line, when OPGW has direct descent from the side of Sirdarya and isolated descent from the side of Novoangren (1 - currents in OPGW directed to the side of Sirdarya from the fault tower; 2 - currents in OPGW directed to the side of Novoangren from the fault tower) 


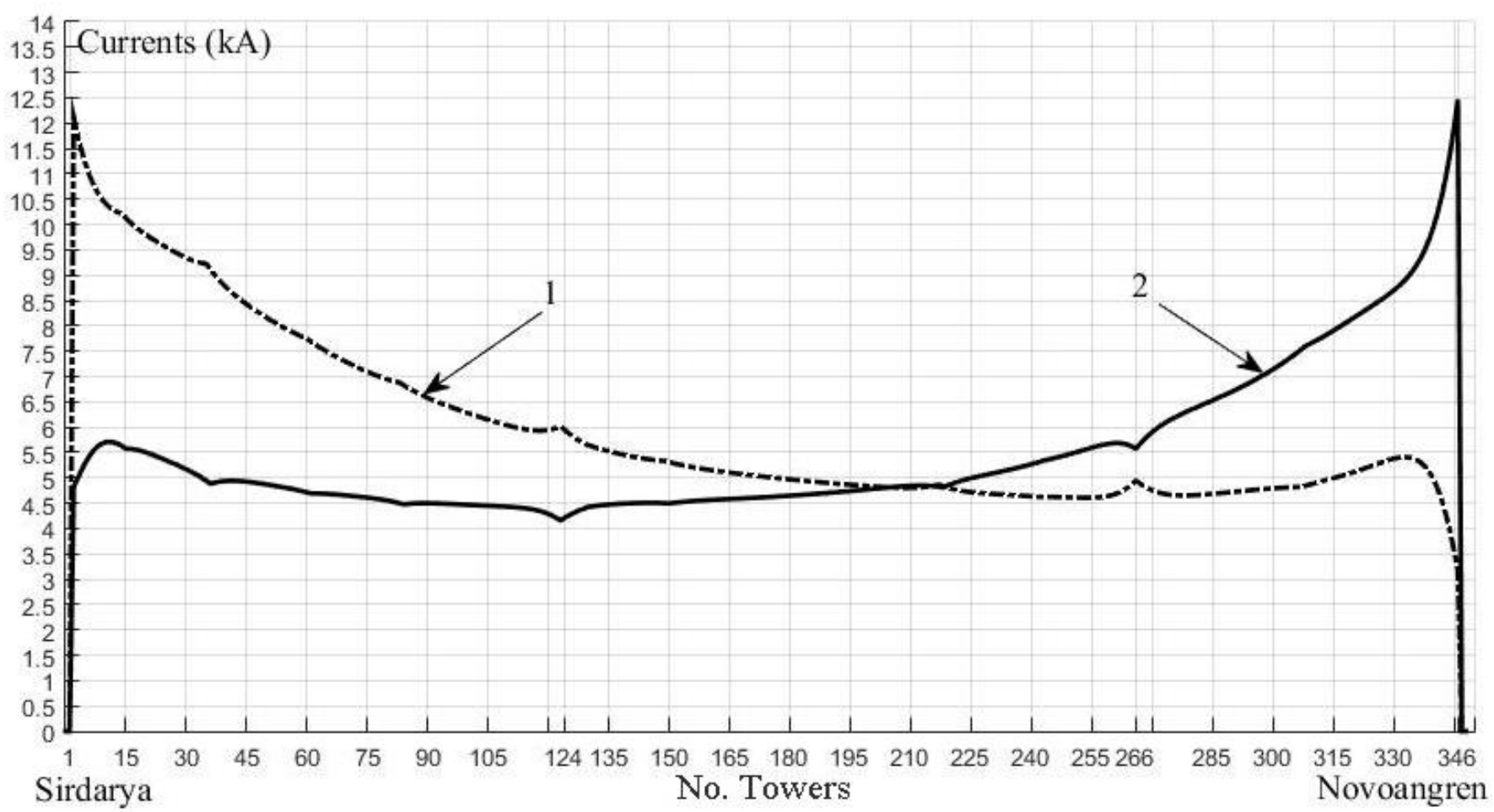

Fig. 8. The fault current distributions in OPGW with stepping movement of the fault point across the line, when OPGW has isolated descents from both ends of the line $(1$ - currents in OPGW directed to the side of Sirdarya from the fault tower; 2 - currents in OPGW directed to the side of Novoangren from the fault tower).

TABLE VI

THE NumeriCAL RESUlts OF FAUlt CURRENTS Distributions IN OPGW FOR DifFERENT DESCENTS FROM THE END TOWERS

\begin{tabular}{|c|c|c|c|c|c|c|c|c|}
\hline \multirow[b]{2}{*}{ Spans } & \multicolumn{4}{|c|}{ Currents in OPGW directed to the side of Sirdarya (kA) } & \multicolumn{4}{|c|}{ Currents in OPGW directed to the side of Novoangren (kA) } \\
\hline & $\begin{array}{l}\text { Direct descent } \\
\text { from Sirdarya } \\
\text { and direct } \\
\text { descent from } \\
\text { Novoangren }\end{array}$ & \begin{tabular}{|c|} 
Isolated descent \\
from Sirdarya \\
and direct \\
descent from \\
Novoangren
\end{tabular} & $\begin{array}{l}\text { Direct descent } \\
\text { from Sirdarya } \\
\text { and isolated } \\
\text { descent from } \\
\text { Novoangren }\end{array}$ & $\begin{array}{c}\text { Isolated descent } \\
\text { from Sirdarya } \\
\text { and isolated } \\
\text { descent from } \\
\text { Novoangren }\end{array}$ & $\begin{array}{l}\text { Direct descent } \\
\text { from Sirdarya } \\
\text { and direct } \\
\text { descent from } \\
\text { Novoangren }\end{array}$ & \begin{tabular}{|c|} 
Isolated descent \\
from Sirdarya \\
and direct \\
descent from \\
Novoangren
\end{tabular} & $\begin{array}{l}\text { Direct descent } \\
\text { from Sirdarya } \\
\text { and isolated } \\
\text { descent from } \\
\text { Novoangren }\end{array}$ & $\begin{array}{c}\text { Isolated descent } \\
\text { from Sirdarya } \\
\text { and isolated } \\
\text { descent from } \\
\text { Novoangren }\end{array}$ \\
\hline Sirdarya -1 & 0 & 0 & 0 & \begin{tabular}{|c|}
0 \\
\end{tabular} & 4.526 & $2.613 \times 10^{-6}$ & 4.526 & $2.613 \times 10^{-6}$ \\
\hline $1-2$ & 13.127 & $2.683 \times 10^{-6}$ & 13.127 & $2.683 \times 10^{-6}$ & 4.263 & 4.825 & 4.263 & 4.825 \\
\hline $2-3$ & 12.603 & 12.107 & 12.603 & 12.107 & 4.510 & 4.983 & 4.510 & 4.983 \\
\hline $3-4$ & 12.151 & 11.745 & 12.151 & 11.745 & 4.760 & 5.151 & 4.760 & 5.151 \\
\hline $4-5$ & 11.765 & 11.433 & 11.765 & 11.433 & 4.987 & 5.306 & 4.986 & 5.306 \\
\hline $5-6$ & 11.438 & 11.168 & 11.438 & 11.169 & 5.1787 & 5.439 & 5.178 & 5.438 \\
\hline$\ldots$ & $\ldots$ & $\ldots$ & $\ldots$ & $\ldots$ & $\ldots$ & $\ldots$ & $\ldots$ & $\ldots$ \\
\hline $343-344$ & 4.471 & 4.471 & 4.668 & 4.668 & 11.102 & 11.102 & 10.881 & 10.881 \\
\hline $344-345$ & 4.112 & 4.111 & 4.364 & 4.364 & 11.647 & 11.647 & 11.367 & 11.367 \\
\hline $345-346$ & 3.681 & 3.681 & 4.005 & 4.005 & 12.299 & 12.299 & 11.947 & 11.947 \\
\hline $346-347$ & 3.205 & 3.205 & 3.615 & 3.615 & 13.074 & 13.074 & $3.494 \times 10^{-6}$ & $3.494 \times 10^{-6}$ \\
\hline 347 - Novoangren & 3.414 & 3.413 & $3.436 \times 10^{-6}$ & $3.436 \times 10^{-6}$ & 0 & 0 & 0 & 0 \\
\hline
\end{tabular}

Fault current distribution characteristics in OPGW show the following.

- At the side of Sirdarya:

when OPGW is grounded from both ends of the line (Fig. 5), in spans on approaching to the substation, the highest values of currents in OPGW occurred when they were directed from the fault point to the side of Sirdarya and reached 13.127 kA. The fault current values directed to the side of Novoangren are relatively smaller course of the big impedance to the side of Novoangren. Current values are changed with moving away of the fault point from the terminals of Sirdarya until about the mid of the line. The isolated descent of OPGW (Fig. 6) allowed decreasing the fault currents in it to the value of $12.107 \mathrm{kA}$ ( $1 \mathrm{kA}$ reduced). At that, the influence of implementing the isolated descent of OPGW on the reduction of currents only from the side of Sirdarya from both ends of the line (Fig. 8) is relatively equal.

- At the side of Novoangren:

when OPGW is grounded from both ends of the line (Fig. 5), in spans on approaching to the substations, the highest values of currents in OPGW occurred when they were directed from the fault point to the side of Novoangren and reached $13.074 \mathrm{kA}$. The fault current values directed to the side of Sirdarya are a relatively small course of the big impedance to the side of Sirdarya, and current values are changed with moving away of the fault point from the terminals of 
Novoangren until about the mid of the line. The isolated descent of OPGW (Fig. 7) allowed decreasing the fault current in it to the value of $11.947 \mathrm{kA}$ ( $1 \mathrm{kA}$ reduced). At that, the influence of implementing the isolated descent of OPGW on current reduction only from the side of Novoangren from both ends of the line (Fig. 8) is relatively equal.

\section{CONCLUSION}

The isolated descent of OPGW allowed decreasing the values of currents in it - this approach helped to reduce the cross section of OPGW and, as a result, to save costs on the project stage.

The cost of OPGW is defined on the basis of its capability to withstand the fault current thermal effect calculated as $I^{2} t$ [13], [14], which also depends on the switching time of the fault. In the present case, this time was unknown; therefore, in order to make a comparison, we $t=0.6 \mathrm{~s}$, basing on the time that is required in the case the main breaker cannot switch off the line and the fault is switched off by the reserve breaker [15].

In our situation, on the side of Sirdarya when OPGW is grounded, $I^{2} t=13.2^{2} \times 0.6=103.28 \mathrm{kA}^{2} \mathrm{~s}$ after implementing the isolated descent of OPGW $I^{2} t=12.1^{2} \times 0.6=87.846 \mathrm{kA}^{2} \mathrm{~s}$, which suggests a thinner wire can be suspended, thus saving the costs.

In this example, only the implementation of the isolated descents of OPGW from the end towers was showed; also, it is possible to implement the descents of OPGW on the towers with high current values in it and to suspend steel GW instead.

When fault current distributions in OPGW were calculated, the type of OPGW was given the same throughout the whole length on the overhead PTL. Therefore, it is necessary to split the line into sections in accordance with the maximal values of the fault current thermal effects on OPGW, taking into account the variant of the selected descents of OPGW from the end towers of the line. On the basis of the calculated values of thermal effect coefficients for those sections of the line, it is needed to repeatedly estimate the selected crosssections of OPGW on fault current thermal effects.

\section{REFERENCES}

[1] IEEE Standard for Testing and Performance for Optical Ground Wire $(O P G W)$ for Use on Electric Utility Power Lines, 1138-2009, Nov. 30, 2009. https://doi.org/10.1109/IEEESTD.2009.5345663

[2] C. A. Crisafulli and D. J. Spoor, "A Case Study on the Appropriate Selection of Optical Ground Wire," in 2008 Australasian Universities Power Engineering Conference (AUPEC'08), Sydney, 2008.

[3] L. L. Henriksen, J. T. Leman and B. H. Berkebile, "Current Rating of Optical Ground Wires," Power Engineers, Inc., Line Conference, March 2008. pp. 1-12. [Online]. Available: https://www.powereng.com (March 2008)

[4] G.-X. Xu, "Single-phase earth fault current distribution between optical fiber composite overhead ground wire and ordinary ground wire in transmission system," J. Chongqing Univ. (Eng. Ed.), vol. 10 no 1 . pp. 78-83, 2011.

[5] IEEE Recommended Practice for Calculating Short-Circuit Currents in Industrial and Commercial Power Systems, 551-2006, Nov. 17, 2006. https://doi.org/10.1109/IEEESTD.2006.248693

[6] G. Egamnazarov, "Calculating the currents in shield wires at short circuits in overhead power transmission lines," Electroenergetica 2013 , Stara Lesna, Slovak Republic, pp. 474-475, 2013.
[7] G. Egamnazarov, "The approach for calculation of asymmetrical modes in multi-wire overhead power transmission lines," in Int. scientific conf., UNITECH-13, Gabrovo, Nov. 22-23, 2013. [Online]. Available: unitech.tugab.bg

[8] J. R. Carson, "Wave Propagation in Overhead Wires with Ground Return," Bell System Technical Journal, vol. 5, issue 4, pp. 539-554, Oct. 1926. https://doi.org/10.1002/j.1538-7305.1926.tb00122.x

[9] J. D. Glover, M. S. Sarma and T. J. Overbye, Power System analysis and design, 5th ed., Stamford, USA: Cengage Learning, 2010.

[10] IEEE Guide to Grounding During the Installation of Overhead Transmission Line Conductors-Supplement to IEEE Guide to the Installation of Overhead Transmission Line Conductors, 524a-1993, July 13, 1994. https://doi.org/10.1109/ieeestd.1994.121457

[11] L. L. Grigsby and A. P. Hanson, "Power Flow Analysis," in Power Systems (Electric Power Engineering Series), L. L. Grigsby (Eds.), 3rd ed., New York: Taylor \& Francis Group, LLC, 2012, ch. 3, pp. 51-61. https://doi.org/10.1201/b12111-5

[12] R. Sitdikov and G. Egamnazarov, "The etalon model for solving currents in ground wires at asymmetrical short circuits on overhead power transmission lines," Elektrofenergetika, Kosice, vol. 9, no. 1, Feb. 2016. [Online]. Available: http://jeen.fei.tuke.sk/index.php/jeen/

[13] T. Thanasaksiri, "Analysis of Overhead Ground Wire Sizes in Distribution Systems," in Proc. 6th Int. Conf. on Electrical Eng./Electronics, Computer, Telecommun. and Information Technology, ECTI-CON 2009, May 6-9, 2009, vol. 1, pp. 92-95. https://doi.org/10.1109/ECTICON.2009.5136973

[14] L. Jie, L. Gang and C. Xi, "Study on the thermal stability of OPGW Under Large Current Condition," in Proc. Pacific-Asia Conf. on Circuits, Communications and System. PACCS 2009, Chengdu, China, May 16-17, 2009, pp. 629-635. https://doi.org/10.1109/PACCS.2009.103

[15] IEEE Guide for Protective Relay Applications to Transmission Lines, C37.113-1999, Feb. 29, 2000. https://doi.org/10.1109/IEEESTD.2000.91147

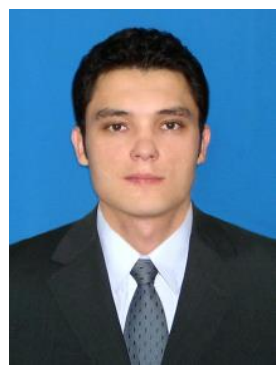

Georgiy Egamnazarov received the B.S. and M.S. degree in electrical engineering from Tashkent State Technical University (Uzbekistan) in 2009 and 2011 respectively. For five years, he has worked as an Engineer Designer at the Design Surveying and Scientific Research company "Sredazenergosetprojekt". Currently, he is a Senior Researcher at the Electrical Power Stations, Networks and Systems Department of Tashkent State Technical University. His main research interests include designing algorithms and software with the implementation of new approaches and modern mathematical methods such as interval analyses for electrical calculations with fuzzy set data.

G. Egamnazarov has participated in internship programs conducting his research at the North China Electric Power University (Beijing, China), Japan, and Malaysia. He is the author and coauthor of thirteen publications.

Address: Electrical Power Stations, Networks and Systems Department,

Tashkent State Technical University, Talabalar str. 2, Room 219, Tashkent, 100095, Uzbekistan.

E-mail: georgiy.egamnazarov@gmail.com 